\title{
Gamificación y elementos propios del juego en revistas nativas digitales: el caso de MARCA Plus
}

\section{Gamification and game-design elements in native digital magazines: the case of MARCA Plus}

\author{
González-Díez, L., Labarga-Adán, I. y Pérez-Cuadrado, P. ${ }^{1}$ \\ Recibido: 26-07-2018 - Aceptado: 18-01-2019 \\ DOI: https://doi.org/10.26441/RC18.1-2019-A3
}

\begin{abstract}
RESUMEN: Cada vez son más los medios de comunicación que recurren a elementos propios del juego para potenciar la interactividad de su producto, fomentar el consumo de contenidos informativos, destacar la publicidad o atraer a una audiencia más joven. Este trabajo pretende evidenciar los elementos y dinámicas de juego que utiliza la revista nativa digital MARCA Plus, publicación multideporte que destaca por su diseño y la adopción de narrativas audiovisuales novedosas. Los resultados muestran la presencia de estos elementos en todos los soportes en los que se ofrece, con una media de juegos por ejemplar muy reducida, asociados todos a contenidos informativos. El juego más empleado es el test deportivo y la media de lectores/usuarios jugadores supera los 200.000 , de los cuales más del $60 \%$ los completa, con una duración media de más de un minuto, si bien no generan conversación posterior en Redes Sociales.
\end{abstract}

Palabras clave: MARCA Plus; gamificación; ludificación; juego; revista digital; periodismo deportivo.

ABSTRACT: It is more and more common for media outlets to draw upon elements that are traditionally found in games so as to enhance the interactivity of their product, foment the intake of their informational content, highlight their advertisements or attract a younger audience. This essay aims to present the elements and dynamics of games that are used by the digital magazine MARCA Plus, a multisport publication that stands out for its design and the adoption of novel audiovisual narratives. The results demonstrate the presence of these gaming elements in all of the platforms in which the magazine is offered with a reduced number of games per issue and all of the games being related to the informational content. The most common game is the sport test, and the average number of readers/users who plays exceeds $200.000,60 \%$ of which complete the game. The average playing time of more than one minute, although they do not tend to generate subsequent conversation on social media.

Keywords: MARCA Plus; gamification; game; digital magazine; sport journalism.

1 Laura González-Díez es Doctora en Ciencias de la Información por la Universidad Complutense de Madrid y Profesora Titular de Diseño Periodístico en la Universidad San Pablo-CEU, CEU Universities. design@ceu.es, http://orcid.org/0000-0003-1209-8845

Ignacio Labarga Adán es Licenciado en Periodismo por la Universidad de Navarra e Investigador en formación en la Escuela Internacional de Doctorado CEINDO, Facultad de Humanidades y CC de la Comunicación. Universidad San Pablo-CEU, CEU Universities. ign.labarga.ce@ceindo.ceu.es, http://orcid.org/0000-0003-2644-6089

Pedro Pérez Cuadrado es Doctor en Ciencias de la Información por la Universidad Complutense de Madrid y Profesor Titular de Diseño Editorial y Visualización de datos en la Facultad de Ciencias de la Comunicación de la Universidad Rey Juan Carlos. pedro.perez@urjc.es, http://orcid.org/0000-0001-7529-6641 


\section{Introducción}

Según la Fundación del Español Urgente (FUNDEU), el término inglés gamification se refiere a la aplicación de mecánicas de juego a entornos no lúdicos y para denominar esta técnica en español se ha empezado a utilizar el calco gamificación que, sin embargo, no parece adecuado, ya que los derivados de juego se forman a partir de la raíz latina ludus (lúdico, ludoteca, ludópata, etc.). Propone entonces utilizar el término ludificación tanto como traducción del término inglés, como en un significado ampliado referido a las iniciativas que pretenden la motivación a través de la diversión en ambientes no propios para ello (como las empresas, la educación o la salud) (FUNDEU, 2012). A pesar de ello, en este trabajo se utilizará el término gamificación que es el que se ha impuesto por influencia del término original inglés.

En este contexto nemotécnico - $\mathrm{y}$ dentro del espectro de publicaciones nativas digitales-, empieza a ser habitual que los medios de comunicación recurran a narrativas gamificadas o ludificadas y a elementos propios del juego con el fin de potenciar la interactividad de su producto, fomentar el consumo de contenidos informativos, destacar sus inserciones publicitarias o atraer a una audiencia más joven. La tendencia es que los cibermedios muestren a sus lectores un porcentaje de la información que ofrecen - y en algunos casos también la publicidadde manera lúdica y participativa, lo que se convierte, además, según Siapera (2012), en un aspecto que re- dunda en el carácter innovador de los contenidos.

Un estudio cuantitativo reciente de los cibermedios en España, publicado por Salaverría et al. (2018), ha localizado 3.431 medios digitales a fecha marzo de 2018, de los cuales 3.065 estaban activos (es decir, se habían actualizado al menos una vez en los últimos tres meses). Entre estos medios se sitúa MARCA Plus, un proyecto de Unidad Editorial que, desde 2014 y con una periodicidad quincenal, se convierte en un caso de interés principal debido al empleo frecuente de elementos propios del juego en sus contenidos.

\section{1. Aproximación al concepto de gamificación}

Un primer acercamiento al concepto de gamificación se encuentra en Deterding, Dixon, Khaled y Nacke (2011, p.2) quienes señalan que "gamification is the use of game design elements in non-game contexts". Si bien es una definición clara y muy sintética, resulta poco precisa ya que no entra ni en las particularidades de los elementos de diseño de juego, ni en su finalidad. Kapp (2012, p.11) sí lo menciona cuando indica que "gamification is using game-based mechanics, aesthetics, and game thinking to engage people, motivate action, promote learning, and solve problems". Es, por tanto, una definición más completa y detallada, ya que introduce las variables de elemento de diseño de juego. Además, este autor apunta ya tres finalidades de la gamificación: motivar la acción, promover el aprendizaje y resolver problemas. 
La gamificación tiene entre sus objetivos influir en el comportamiento de las personas, a través de las experiencias y sentimientos que se construyen a través del juego incentivando el compromiso y la fidelidad de usuarios, clientes o trabajadores (Ramírez, 2014) y actuando "sobre la motivación para la consecución de objetivos concretos" (Teixes, 2015, p.18). Así pues, la gamificación comprende la selección de elementos que incorporan los juegos con el fin de crear estrategias participativas (TorresToukoumidis, 2016).

Para Rieber (1996, p.51) "playing a game successfully can require extensive critical thinking and problema-solving skills", es decir, los juegos tienen una funcionalidad social, ya que el pensamiento crítico y las habilidades para solucionar problemas pueden ser utilizados en los mismos. Para este autor, los juegos poseen una organización estructurada con interacciones complejas en las que se incluye un contexto, unos jugadores, objetos, metas, reglas, condiciones y un reto. Y son precisamente estos los componentes que se encuentran dentro del proceso de diseño de gamificación.

Burke (2014, p.6), por su parte, define la gamificación como "the use of game mechanics and experience design to digitally engage and motivate people to achieve their goals". En este sentido, se puede decir que si bien es obvio que el desarrollo de las nuevas tecnologías ha favorecido que la mayor parte de las dinámicas que se están empleando se vinculan a recursos digitales, esto no quiere decir que sea requisito indispen- sable emplear las TIC en la gamificación de contenidos. Ahora bien, "las nuevas tecnologías han contribuido a que la gamificación evolucione, incluyendo la narrativa transmedia. El juego no tiene que desarrollarse necesariamente de manera estática, sino que permite la inclusión de dispositivos tan comunes y cotidianos como el smartphone o la tablet. Esta circunstancia abre nuevas posibilidades para atraer a aquellas generaciones acostumbradas al uso de las tecnologías" (Rodríguez-Fernández, 2017, p.182).

Para algunos autores (TorresToukoumidis, 2016) hay que remontarse a 1938 para encontrar los orígenes de los estudios sobre gamificación, momento en que Huizinga publica Homo Ludens, donde se estudian por primera vez los elementos de los juegos separados del juego per se y dentro de un contexto diferente, que en este caso era la cultura. La relevancia de Huizinga (1938, p.11) radica en que hace referencia por vez primera a los elementos del juego: "the words we use to denote the elements of play belong for the most part to aesthetics, terms with which we try to describe the effects of beauty: tension, poise, balance, contrast, variation, solution, resolution, etc.", con lo que dio el primer paso para establecer la estructura de los elementos de los juegos.

En 1973, Coonradt funda la firma Game of Work, en la que por primera vez se buscan soluciones de productividad, rendimiento y satisfacción de personal de las empresas a través de técnicas empleadas en los deportes y en la recrea- 
ción. Coonradt toma la iniciativa de trasladar los elementos de los juegos al ambiente laboral, una idea revolucionaria que será abordada en detalle en el siglo xxi por autores como Zichermann o Herger, entre otros (TorresToumoukis, 2016).

Ya en los años ochenta del siglo pasado, Malone se da cuenta del potencial de los juegos de ordenador para motivar el aprendizaje. Centra sus estudios en los elementos que, al ser divertidos para las personas, acaban por motivarlas y empujarlas a la acción. En estas investigaciones, Malone (1980) ya demuestra la existencia de tres categorías que determinan la motivación: la curiosidad, la fantasía y los retos.

En los años noventa, es Rieber (1996) quien escribe un ensayo en el que manifiesta el papel esencial que desempeñan los elementos de los juegos en cuanto mediadores de la enseñanza de las personas en su vida diaria.

En 2002 se funda la Serious Games Initiative (SGI) cuya finalidad era desarrollar juegos con propósitos formativos. Como señala Torres-Toukoumidis (2016) esta asociación, pionera de los juegos formativos - sobre todo digitales-, se consolida en el mercado gracias a un proyecto encargado por el ejército norteamericano con el objetivo de motivar el alistamiento voluntario a sus filas. Y más allá de estos inicios en el campo de la defensa, los serious games pueden adaptarse a cualquier ámbito social, como es el caso de la política o la enseñanza.

2003 es el año en el que aparece en escena el término gamification, acuñado por Pelling, quien en sus trabajos de programación informática para la empresa Conundra Ltd. diseña interfaces informáticos a través de elementos de diseño de juego. En estos momentos, el término se asociaba aún al diseño informático (Torres-Toukoumidis, 2016).

Fue en 2010 cuando empezaron a aparecer investigaciones académicas sobre gamificación, abordando sus orígenes, su diseño, sus elementos, su empleo y su contexto. Es entonces cuando "por primera vez se acepta la gamificación como un fenómeno emergente que tiene las herramientas para cambiar las experiencias en los sistemas de interacción humana" (Torres-Toukoumidis, 2016, p.121).

La primera conferencia oficial de gamificación tiene lugar en 2011, y ese mismo año, el Diccionario de Oxford agrega la palabra gamification, definiéndola como "the application of typical elements of game playing (e.g. point scoring, competition with others, rules of play) to other areas of activity, typically as an online marketing technique to encourage engagement with a product of service". A día de hoy es el único diccionario que ha conceptualizado el término.

Desde ese momento se inicia el despegue de los estudios e iniciativas sobre este fenómeno y son numerosos los autores que teorizan sobre ello: Werbach y Hunter (2012), Huotari y Hamari (2012), Kapp (2012), Paharia (2013), Zichermann y Linder (2013) o Marczewski (2015), los cuales divulgan los beneficios del empleo de elementos propios de los juegos en diferentes 
áreas de la sociedad. A la par, son muchas las empresas (Starbucks, Amazon, Google, Samsung, Volskwagen, entre otras) que empiezan a emplear técnicas de gamificación, tanto en la publicidad como en su departamento de recursos humanos, tanto para fidelizar a los clientes como para motivar a sus empleados. A ello se suma la aparición de cursos, seminarios y jornadas especializados en todo el mundo. En el caso de España destaca como pionera la Fundación UNED con un curso sobre gamificación, que en febrero de 2018 celebró su séptima edición y la Escuela de Negocios de la Innovación y los Emprendedores (IEBS) que cuenta con un máster de Gamificación y Narrativa Transmedia. Como colofón, en 2012 se celebró la primera edición del Gamification World Congress, que en 2013 se trasladó a Madrid, en 2014 a Barcelona y, en otoño de 2017, volvió a Madrid.

Finalmente, se reseña la existencia -desde 2006- de una plataforma, la World Gamification Map, con 67 proyectos expuestos y que funciona como repositorio internacional de proyectos de gamificación con fines divulgativos y de investigación. Se puede acceder a esta plataforma en línea desde: http://www. gamificationworldmap.com. Lo cierto es que el fenómeno de la gamificación invade territorios de la comunicación cada vez con más fuerza e insiste en la idea de la narrativa transmedia tanto en medios tradicionalmente escritos como en los audiovisuales (Martínez Cano, 2016b).

\section{2. El empleo de elementos del juego como estrategia narrativa en diarios y revistas}

Uno de los sectores más afectados en las últimas décadas por la crisis económica ha sido el de los diarios y las revistas, teniendo que hacer frente, de un lado, a una notable reducción del número de lectores y, de otro, al descenso constante de las inversiones publicitarias. Ante este escenario, la innovación desempeña un papel esencial para intentar conseguir más audiencia y es ahí donde la gamificación —o ludificación- entra en juego, y permite a los cibermedios generar estrategias narrativas que hagan su producto más interesante, no sólo para los lectores - a quienes sitúa en el centro de la experiencia- sino también para los anunciantes. La adopción de mecánicas propias del juego para favorecer la participación de los lectores empieza a ser una constante en el periodismo.

En palabras de Ferrer Conill (2016, p.46):

...several news media have started to introduce gamification techniques into their digital platforms as a new storytelling format for news consumption. Since habit strength is the most powerful predictor of news consumption, the goal is to not only engage news consumers, but also to provide a personalized news experience and to persuade users to foster the habit of consuming news regularly.

Por su parte, García-Ortega y GarcíaAvilés (2018: p.152) señalan que:

...en este ecosistema de cambio e innovación, surgen diversos formatos 
influidos por la narrativa y la estética de los videojuegos. Es lo que se conoce como gamificación, una forma diferente de presentar el contenido que mejora la motivación de los usuarios y favorece su participación.

Según Martínez Cano (2016a, p.160), el fenómeno de "la gamificación en España ha cobrado un papel principal en los nuevos modelos de negocio. Actualmente, España se sitúa en el segundo lugar después de EEUU en el uso, empleo e innovación de múltiples sectores a través de la gamificación”. Considera evidente "el declive de las industrias de comunicación clásicas arrastradas por los nuevos medios digitales, por lo que la gamificación de las noticias se presenta como pieza clave $y$ principio de discontinuidad para propiciar un nuevo modelo comunicativo de consumo". Para este autor, dentro de este nuevo fenómeno existe ya una primera clasificación de géneros, pudiendo diferenciar entre serious games, docugames, reality games, political games $\mathrm{e}$ interactive infographics, cada uno de los cuales presenta características propias, pero todos parten de la idea de explorar la fusión de las prácticas periodísticas y el videojuego para generar nuevas estrategias de comunicación (Martínez Cano, 2016a), y lo hacen a partir del empleo de elementos tradicionales como los textos, las fotografías, las ilustraciones, el color, a los que se suman los sonidos, las imágenes en movimiento y la interactividad que permiten las nuevas tecnologías.

Por su parte, Ferrer Conill recoge que "traditional newspapers have a long history of incorporating games, among which quizzes and puzzles are the most popular. The introduction of digital technologies has derived into two formats: newsgames and gamified news. The difference (...) is that newsgames are computer games used to participate in the public sphere with the intention of explaining or commenting on current news, while gamification does not attempt to create a fullfledged game but simply to apply game elements to digital interfaces that endeavor to merge both news and games in new storytelling formats using game mechanics as a defining feature" (Ferrer Conill, 2016: p.47).

Abundando en los newsgames, GarcíaOrtega y García-Avilés (2017) opinan que son un formato interactivo que bebe del videojuego y el periodismo para mostrar la información de una forma lúdica, inmersiva y participativa. Para estos autores, a diferencia de las noticias gamificadas, los newsgames reúnen todas las condiciones necesarias para ser considerados videojuegos de pleno derecho. Se presentan, por tanto, como una extensión del relato periodístico que permite al usuario experimentar de primera mano con la información.

En España, los medios de comunicación que más están apoyando estos nuevos discursos informativos a partir de estrategias y dinámicas basadas en el juego son: El Confidencial Lab y el Lab de Radio Televisión Española (RTVE). En el panorama internacional, la $B B C$, The New York Times, The Guardian o Al Jazeera, son algunos de los casos más relevantes en lo que a gamificación de 
contenidos informativos se refiere (García-Ortega y García-Avilés, 2018b; Ferrer Conill, 2016). En lo que a prensa deportiva se refiere, MARCA Plus es un caso significativo ya que se trata de una publicación que, frente a sus competidoras en el mercado, realiza "un tratamiento de la información deportiva mucho más ameno aprovechando las potencialidades tecnológicas para la interacción y creando espacios para la gamificación de los contenidos" (Rojas Torrijos, 2015: p.46).

\subsection{El caso de MARCA Plus}

Tras ser reconocida por Apple como una de las mejores apps para iPad en 2014 y ganar los Digital Magazine Awards en 2015 y 2016 (en la categoría "mejor magazine de deportes"), MARCA Plus se ha convertido en un referente para las publicaciones nativas digitales. A estos logros se suma el de ser finalista en los Premios García Márquez de Periodismo (categoría "Innovación”) y su distinción con una 'Special Mention' en los "European Digital Media Awards" (mejor publicación para tabletas). Esta revista es una de las grandes apuestas de Unidad Editorial por las nuevas tecnologías, habiendo conseguido, con cerca de 97 números en 43 meses, un posicionamiento excepcional en el mercado digital con una media de 195.000 descargas por número y más de 13 millones de descargas desde su lanzamiento —según datos aportados por los responsables de la propia revista en marzo de 2018-.

MARCA Plus es una publicación multideporte, aparecida en agosto de 2014, que desde entonces se edita para iPad y otros soportes móviles, con una periodicidad quincenal. Se caracteriza por la primacía de lo audiovisual en sus contenidos y destaca por la calidad de sus reportajes y entrevistas, así como por la apuesta por el fotoperiodismo y el periodismo de datos. Se trata de una publicación cien por cien interactiva que destaca por su diseño, creatividad, carácter innovador, interactividad, nuevas narrativas audiovisuales, la importancia que concede a la imagen y también por sus contenidos. Para Rojas Torrijos (2018) es de destacar el carácter pionero de MARCA Plus en la experimentación de nuevas fórmulas narrativas, que tienden a aproximar al lector a la actualidad informativa de forma amena y, a la vez, procurarle una experiencia diferente de navegación entre la multitud de posibilidades interactivas que la publicación ofrece. A todo ello se suma el hecho de ser un soporte ideal para las nuevas tendencias en publicidad, convirtiéndose en un interesante modelo de negocio en el panorama actual de la comunicación digital.

Se trata de una revista de contenidos premium (protagonistas mundiales, lyfestyle, publicidad interactiva y entretenimiento), cuyos cuatro pilares básicos son: profundidad, creatividad, interacción e innovación. Según Labarga, González-Díez y Pérez-Cuadrado, MARCA Plus ofrece:

...una experiencia única de usuario en la que el lector elige los contenidos que quiere leer. La revista, disfrutada al completo (leyendo todos los textos, viendo todas las imágenes, infografías 
y vídeos) puede durar hasta tres horas. En cuanto a contenidos deportivos aparecen siempre unas cinco entrevistas a grandes protagonistas (de todos los deportes), infografías, reportajes, juegos interactivos y videorreportajes. Contenidos únicos y exclusivos pensados directamente para aprovechar los recursos que ofrece este tipo de soporte (Labarga et al., 2018).

Estos pilares se ponen de manifiesto en el creciente empleo de elementos propios del juego en los contenidos de la revista con el fin de atraer más lectores, motivarlos, aumentar su participación y hacer que permanezcan más tiempo en la revista, así como conseguir una mayor fidelización con la cabecera.

\section{Objetivos y Metodología}

El principal objetivo de este artículo es abordar el empleo de elementos propios de los juegos por parte de la revista nativa digital MARCA Plus, tanto en los contenidos informativos como publicitarios, identificando el tipo de juego utilizado. Se trata también de determinar si la cabecera objeto de estudio ofrece a sus lectores espacios con contenidos gamificados.

Como objetivos secundarios nos planteamos determinar:

- si los elementos propios del juego están presentes en todos los soportes en los que se ofrece la revista,

- la frecuencia de juegos por número,

- la situación del contenido informativo o publicitario gamificado, y de los juegos, por secciones o bloques temáticos,
- los efectos multimedia e interactivos empleados en los elementos propios del juego utilizados,

- el número de usuarios que acceden a jugar, si completan el juego y la duración del mismo,

- si existe un reto que motive el juego y hay una recompensa,

- cuál es la opinión de los suscriptores sobre el empleo de estos elementos y si el juego genera conversación posterior en redes sociales.

- quién decide la incorporación de los juegos, quién los diseña, cuál es el proceso que se sigue en su realización,

- qué criterios hay en la revista en torno al empleo de elementos propios del juego.

En cuanto a las hipótesis de partida, planteamos las siguientes:

H1. La revista nativa digital MARCA Plus ofrece a sus lectores contenidos gamificados y elementos propios de los juegos en las distintas plataformas en las que está disponible, con el fin de obtener un mayor interés por parte de los lectores, fidelizarlos y hacer más atractivos los contenidos informativos y publicitarios para ellos.

H2. La presencia de contenidos gamificados, así como el empleo de recursos propios del juego en la información y en la publicidad, permite crear situaciones de comunicación que motivan a los públicos/usuarios/espectadores a expresar sus sentimientos y pensamientos. A través del empleo de juegos interactivos en cada ejemplar, MARCA Plus pretende crear experiencias atractivas que inspiren a la acción e involucren al usuario. 


\subsection{Propuesta metodológica}

En cuanto a la metodología utilizada, se plantea un estudio de caso a través de recursos variados - entrevistas, observación participante, cuestionarios o documentos bibliográficos- que permiten una visión holística del objeto de estudio. Se ha acudido a la observación participante, en cuanto herramienta útil para recoger datos directamente del escenario elegido para nuestra investigación, participando en todos los procesos de creación y producción de la revista en los números que conforman la muestra, por lo que ha sido posible conseguir la información desde dentro a partir de un estudio exploratorio de los contenidos.

Por otro lado, se ha acudido a técnicas de análisis de contenido, tanto cuantitativas como cualitativas, para la recogida de datos procedentes de los contenidos informativos y publicitarios del universo de MARCA Plus. Se ha realizado una encuesta a los suscriptores para conocer aspectos subjetivos como sus opiniones y actitudes sobre la experiencia de usuario (UX). Para la selección de la muestra se envió el cuestionario a todos los suscriptores de la revista que conforman un universo de 222.000 sujetos, por tanto, se pretendía que toda la población objeto de estudio formara parte de la investigación. El resultado obtenido fueron 150 individuos que respondieron al cuestionario, lo que supone, en términos de muestreo para un $\mathrm{N}=222.000$, un margen de confianza de $95 \%$ que implica que la puntuación $\mathrm{Z}-\mathrm{o}$ cantidad de desviaciones estándar que una proporción determinada se aleja de la mediasea de 1,96 y un margen de error de $8 \%$
— se entiende que hubiese sido más representativo un margen de error de $5 \%$, lo que supondría un total de 384 individuos encuestados, que con un margen de confianza de $95 \%$ se estaría en los estándares habituales en este tipo de investigación. Pero es necesario recordar que la encuesta fue enviada a la totalidad de la población objeto de estudio-. El cuestionario contaba con siete preguntas ya que se pretendía conocer nivel de satisfacción de los juegos ofrecidos por la revista MARCA Plus y se necesitaban pocas preguntas que resultaran de fácil respuesta. Tan solo dos preguntas eran abiertas, en las que el sujeto podía opinar al respecto de su grado de satisfacción. El resto de preguntas eran dicotómicas y politómicas de rápida contestación. Se obvió cualquier tipo de pregunta sociodemográfica pues no era el propósito de la investigación ni de los objetivos planteados anteriormente.

Finalmente, señalar que durante la fase exploratoria de la investigación se empleó la entrevista como técnica de recogida de datos. Se procedió a entrevistar a los diseñadores de la revista y de los distintos juegos incorporados en ella (Rafael Barroso y Fernando Bel), y al fundador de la publicación - Nacho Labarga, coeditor de la cabecera desde su nacimiento hasta septiembre de 2017-. Para ello se preparó una entrevista semiestructurada - ya que este tipo de entrevista es más abierta y flexible y permite introducir temas nuevos que inicialmente no estén contemplados pero que podrían surgir durante la conversación-, con un total de ocho preguntas abiertas, que se realizó en marzo de 2018, en la sede de la revista. 
Por otro lado, para conocer los elementos propios del juego que aparecen en las unidades de análisis seleccionadas, se diseñó una ficha ad hoc como instrumento que permitiera la recopilación de datos. Dicha ficha contemplaba como variables los diferentes elementos que podían intervenir en el juego, así como el tipo de juego; el número por ejemplar, el bloque temático en el que aparecían, si se vinculaban a contenidos informativos o publicitarios, la descripción del juego, los efectos de interactividad empleados en el mismo, el número de visitas/usuarios por cada uno de ellos, el tiempo de permanencia, si los lectores/usuarios los completan o si obtienen algún tipo de recompensa.

Para realizar dicho análisis de contenido se ha elegido una muestra por conveniencia, centrada en los 25 primeros números de esta cabecera. Hay que tener en cuenta que el universo de los números editados desde el nacimiento de la revista (20 de agosto de 2014) y el 15 de marzo de 2018, momento del cierre de este trabajo, supone un total de 97 nú- meros. La razón de esta elección hay que buscarla en el conocimiento cierto de que, a partir de la vigesimosexta edición, MARCA Plus no incorpora formatos diferentes de los juegos ofrecidos, lo que permite asegurar que los resultados extraídos de la muestra son cien por cien extrapolables al total de la publicación.

\section{El empleo de contenidos gamificados y de elementos propios de los juegos en MARCA Plus. Resultados}

El principal resultado derivado del análisis cualitativo y cuantitativo realizado sobre la muestra elegida es que la revista nativa digital MARCA Plus no emplea estrategias de gamificación en los contenidos que ofrece a sus lectores, si bien, sí hemos constatado el empleo de los juegos como complemento lúdico de la información.

Por otro lado, la aplicación de la ficha de variables diseñada para conocer el empleo de elementos propios de los juegos en la revista objeto de estudio, nos ha permitido obtener los siguientes resultados:

Figura 1. Contenidos gamificados por ejemplar

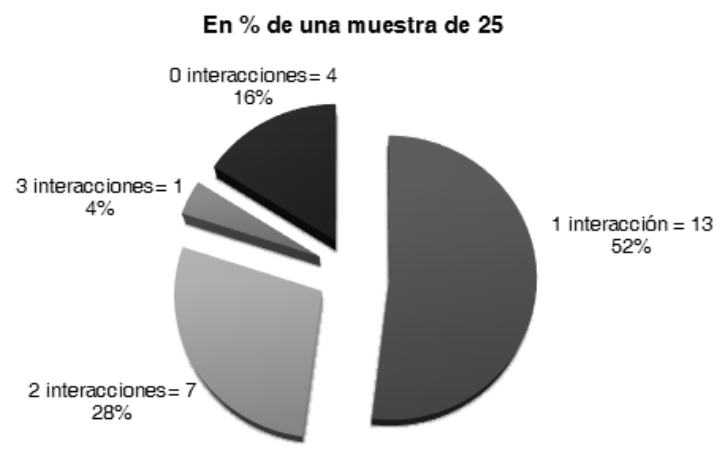

Fuente: Elaboración propia. 
A. Desde el punto de vista del tipo de soporte En los 25 números que componen la muestra se han detectado 30 casos y, en todos ellos, el empleo de los juegos está presente en los tres soportes desde los que se puede acceder a la revista: desktop, smartphone y tablet, lo que pone de manifiesto el interés de la cabecera analizada en adaptar el diseño de la publicación a los diferentes formatos.

\section{B. Desde el punto de vista de la frecuencia de} juegos por ejemplar

En cuanto a la presencia de juegos por ejemplar, hay que señalar que no hay ningún juego en un $16 \%$ de los ejemplares analizados; hay un caso en el $52 \%$; y dos en el 28\%. Tan solo en un 4\% de los ejemplares analizados hay tres casos. Esto supone una media de 1,6 juegos por ejemplar.

\section{Desde el punto de vista de la situación en la revista}

Por su carácter de revista quincenal, MARCA Plus se aleja un poco de las noticias y la actualidad inmediata y apuesta por contenidos como entrevistas, reportajes (y videorreportajes), columnas de opinión, fotogalerías, infografías, encuestas y juegos interactivos. Tal y como recogen Labarga et al. (2018) cada número suele contar con una media de cien pantallas en total (93 de media de información y 7 de publicidad) y unos 45 artículos; suelen aparecer cuatro o cinco entrevistas (se intenta que los protagonistas sean de diferentes deportes), unos diez reportajes, al menos una columna de opinión, una tema histórico, dos o tres infografías, un videorreportaje y algunos juegos interactivos con los que se pretende enganchar al usuario o poner a prueba sus conocimientos deportivos. Todos estos contenidos se agrupan en 12 secciones (portada, editorial, flash, fotoshots, la entrevista, los cuartos, videoencuesta, flashback, cuestión de coco, el rincón del modesto, se escuchó en Radio MARCA y staff) que a su vez se agrupan en cuatro bloques temáticos (bloque de apertura; bloque de futbol; bloque polideportivo y bloque comercial).

Figura 2. Ubicación de los juegos en los bloques de MARCA Plus

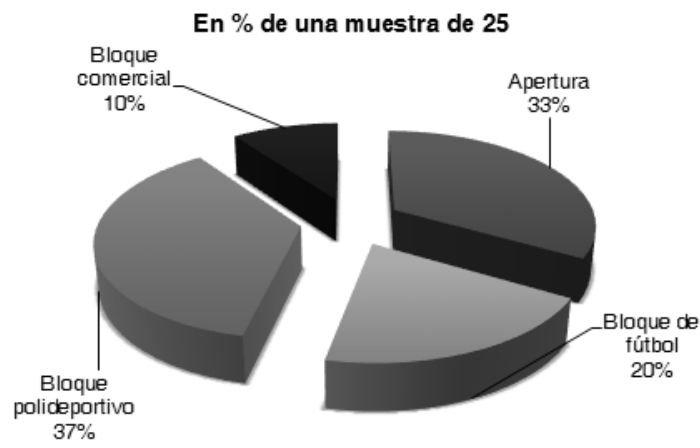

Fuente: Elaboración propia. 
En cuanto a los casos analizados hay que señalar que el 33,33\% se sitúa en el primer bloque; el 20\% en el segundo; el $36,66 \%$ en el tercero y tan solo el $10 \%$ en el último. Lo que indica que sucede lo mismo que en el mundo impreso, donde se consideran las primeras páginas más interesantes que las de cola.
D. Desde el punto de vista del tipo de juego Tras el trabajo de campo realizado, podemos establecer los siguientes grupos de juegos: test deportivo (40\%); adivinanzas (26,6\%); cartas $(26,6 \%)$ y el test por gustos $(6,6 \%)$.

Figura 3. Tipos de juegos empleados en MARCA Plus

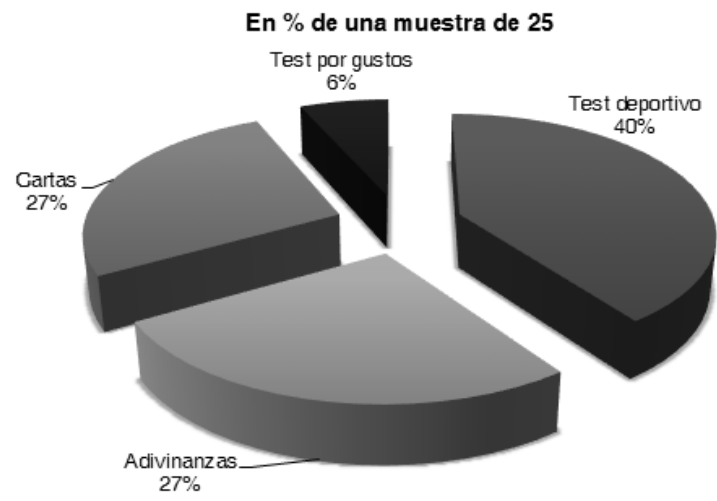

Fuente: Elaboración propia.

Figura 4. Test deportivo (no 2, 1 de septiembre 2014)

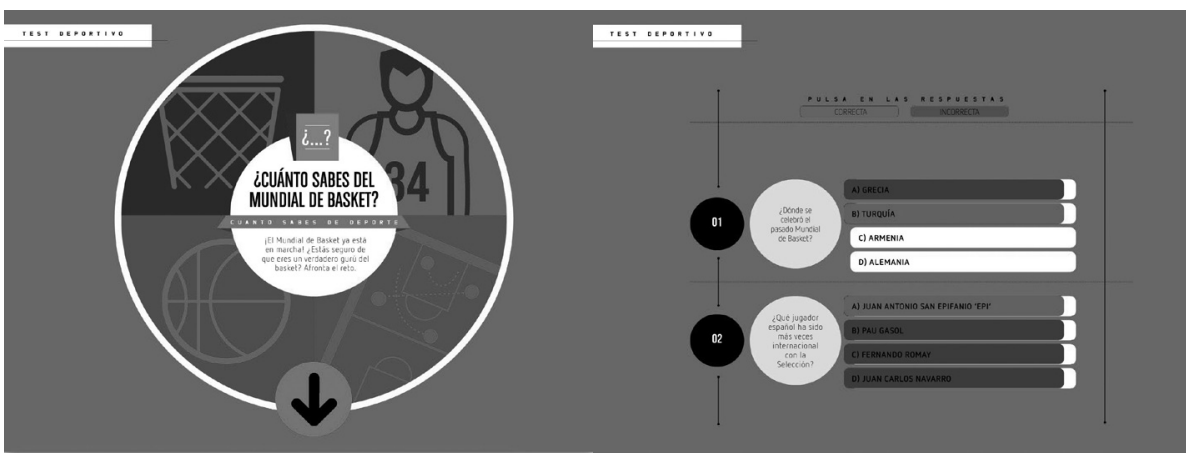

Fuente: MARCA Plus, http://plus.marca.com/numero2 


\section{- Test deportivo}

Consiste en un cuestionario deportivo en el que, según el número, se hace sobre deporte en general o alguna disciplina en concreto. Se formulan 10 preguntas con cuatro respuestas posibles para cada una en la que, según pulsa el usuario, sale en verde - si es correcta- o en gris — si es negativa-. Se busca que el usuario demuestre y refresque sus conocimientos e incluso que los comparta con un amigo o se rete con él para saber quién sabe más en función de quién haya acertado más respuestas.

\section{- Adivina quién y quién soy}

Es otro ejemplo de utilización de elementos propios del juego en la información en MARCA Plus. El 'adivina quién' se usa de varias maneras. La más habitual consiste en incluir la frase pronunciada por un deportista con tres opciones diferentes. El usuario debe activar el play para escucharla y después intentar adivinar quién de los tres deportistas es el autor. Si acierta, recibe un aplauso y aparece el signo de acierto, mientras que si falla aparece una ' $x$ ' roja de error y un sonido que desvela su equivocación. También aparece en otros formatos como la silueta de un escudo que hay que adivinar a qué equipo pertenece, una frase concreta que hay que relacionar con el autor de la misma o la cara infantil de un deportista al que hay que relacionar con su nombre.

Figura 5. Adivinanza (no 5, 15 octubre 2014)

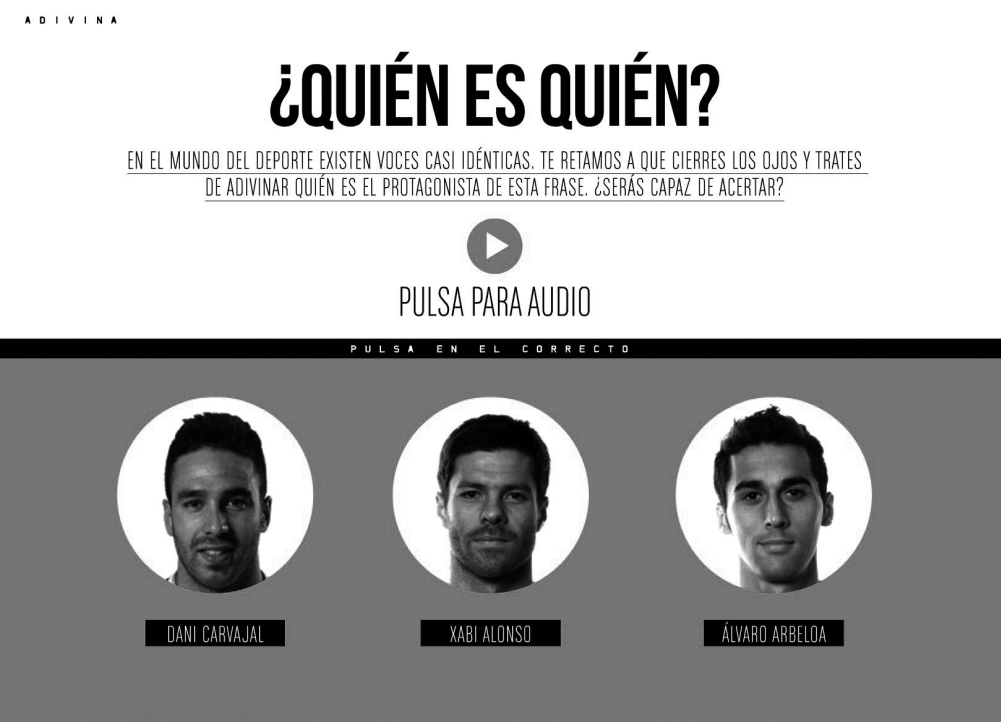

Fuente: MARCA Plus, http://plus.marca.com/numero5 
Figura 6. Adivinanza (no 16,1 abril 2015)

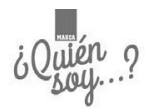

\section{¿QUÉ FUTBOLISTA SE OCULTA TRAS ESTE ANGELICAL ROSTRO?}

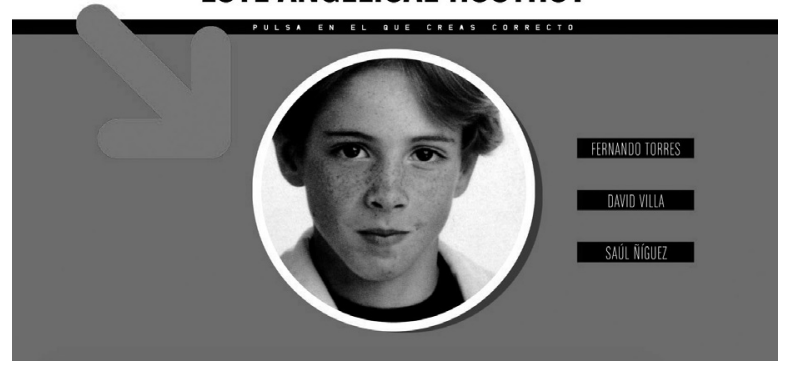

Fuente: MARCA Plus, http://plus.marca.com/numero16

Figura 7. Adivinanza (no 23, 1 de julio de 2015)

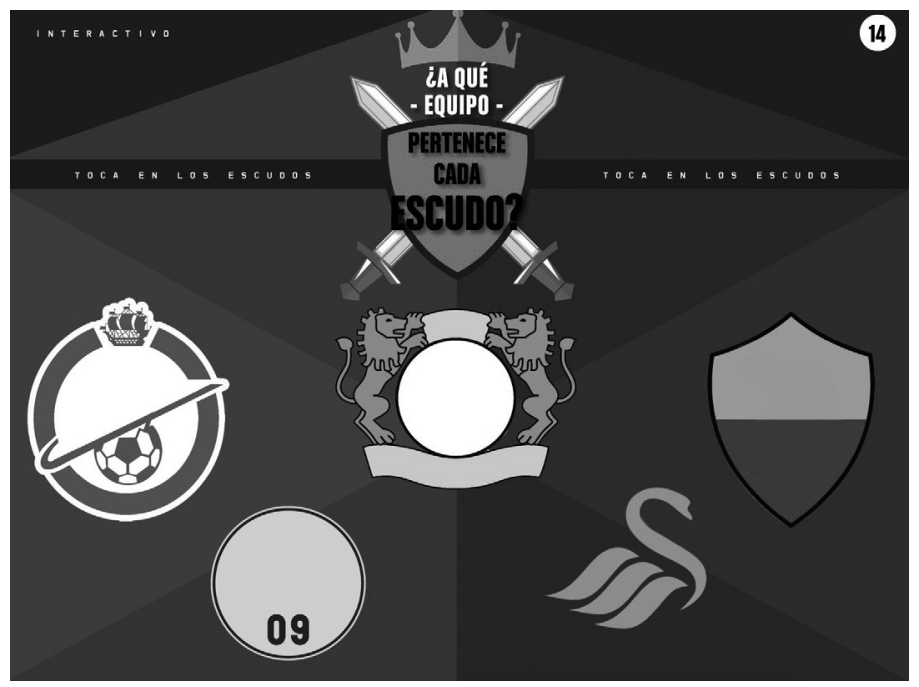

Fuente: MARCA Plus, http://plus.marca.com/numero23 


\section{- Cartas}

En este tipo de juegos se trata de emparejar una opción con otra. Es muy recurrente y se usa para emparejar futbolistas con sus equipos, deportistas con sus parejas, con sus sueldos, etc. Si se acierta, el usuario recibe un aplauso y, si se falla, un sonido que pone de manifiesto el error.

Figura 8. Cartas (no24, 15 de julio de 2015)

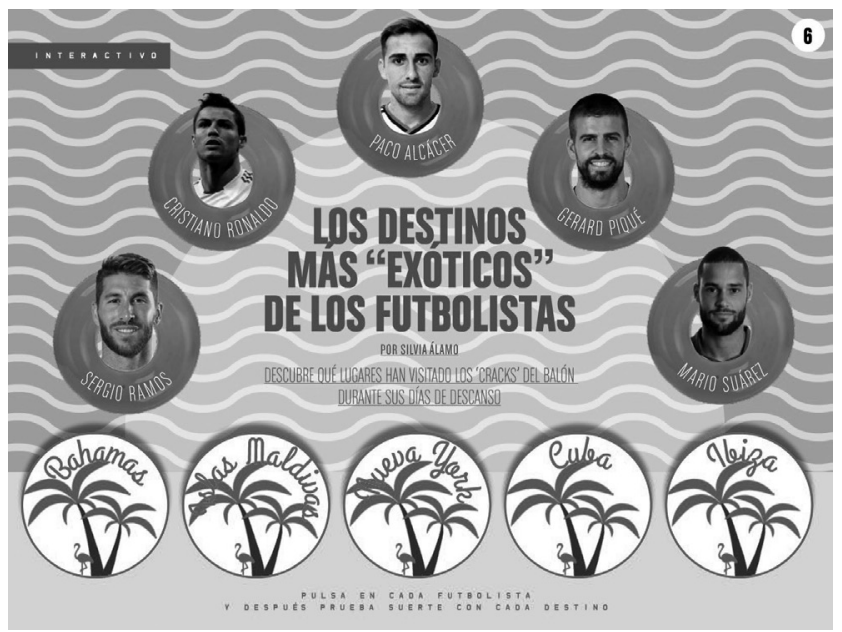

Fuente: MARCA Plus, http://plus.marca.com/numero24

\section{- Test por gustos}

Este modelo de juego incorpora un árbol en el que el usuario va avanzando según elige varias opciones según sus gustos o preferencias. Se ha empleado en los números de temática especial (Giro de Italia de ciclismo y Mutua Madrid Open de tenis) para relacionar al usuario con el deportista al que más se asemejaría según sus preferencias.

Finalmente, podemos señalar que los juegos incorporados en la revista objeto de estudio pueden clasificarse en tres grupos:

El primero estaría integrado por aquellos juegos (grupo A y B) que buscan que el usuario muestre sus conoci- mientos deportivos de diferentes maneras (escuchando una voz y asociándola con su autor, emparejando a deportistas con sus ex equipos, a deportistas con sus parejas, a políticos con sus equipos, respondiendo cuestionarios, señalando a qué deportista corresponde una foto en concreto, cuál es la imagen original...).

El segundo agrupa aquellos juegos (grupo C) que pretenden que el usuario elija según sus gustos unas opciones para que el juego establezca a quién se parece más el usuario. Aquí no entrarían en práctica los conocimientos, no los tendría que demostrar, sino simplemente avanzar en base a las preferen- 
cias de cada usuario.

Y el tercer grupo de juegos (grupo D) estaría integrado por aquellos que, simplemente, permiten al usuario/lector in- teractuar mediante un efecto multimedia para poder descubrir un contenido publicitario a través del cual después se pueden comprar esos productos.

Figura 9. Test por gustos (no 74, 1 de mayo de 2017)

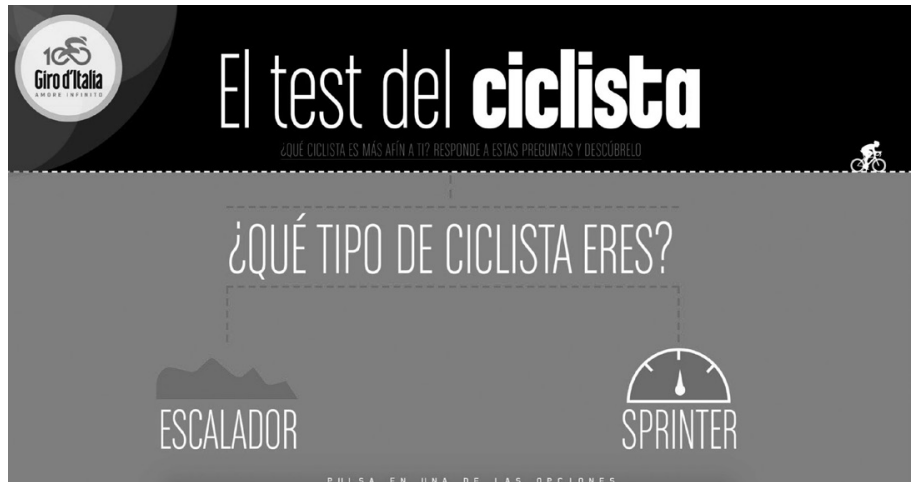

Fuente: MARCA Plus, http://plus.marca.com/numero74/\#/spreads/55

\section{E. Desde el punto de vista de los contenidos}

El análisis realizado indica que los elementos propios del juego se han empleado únicamente en contenidos de carácter informativo (100\%), no alcanzando en ningún caso a la publicidad. No obstante, en un análisis exploratorio posterior, se ha podido comprobar que en los números 63, 64, 65, 77 y 91 -que no formaban parte de la muestra- sí hay contenidos publicitarios que han recurrido a elementos propios de los juegos. Concretamente, consistían en implicar al lector/usuario en la búsqueda de algún elemento entre las diferentes páginas/pantallas de la revista-en el caso concreto del no 63 un 'sobre de oro FIFA17' - y cuando se encontraba, se instaba al lector a hacer una captura de pantalla y enviarlo a la revista para poder entrar en el sorteo de una recompensa (códigos del videojuego FIFA17 en caso de los números 63 y 64 o un balón firmado por Gasol en el no 65). En el no 77 se pedía al usuario encontrar una gafas de sol escondidas en la revista y mandar la captura de pantalla, una vez encontradas, a la dirección de correo electrónico de la revista para entrar en el sorteo.

Por último, en el no 91 hay otro ejemplo de contenido publicitario que acude a elementos propios de los juegos. Se trata de un reportaje de brandend content en el que, para poder disfrutarlo, había que rascar o borrar la pantalla que está llena de crema Nivea (en versión smarthphone y tabletas) porque en PC hay que pulsar sobre la pantalla para que la espuma desaparezca - no 
como en las otras versiones que la puede quitar el usuario con el dedo- y se pueda visualizar la página para poder disfrutar del reportaje patrocinado. También se pueden arrastrar los productos que hay en la estantería al carro de compra e, incluso, comprarlos a través de los respectivos links a la web de la marca.

F. Desde el punto de vista de los efectos multimedia y de interactividad empleados

En cuanto a los efectos multimedia se adoptan como categorías (Labarga et al., 2018): la galería de imágenes (sucesión de fotos de una temática particular en la que, para pasar de una foto a la siguiente, se requiere de la interacción del usuario deslizando el dedo — si está en móvil o tableta- o el ratón —si está en la versión PC—; la animación en autoplay (imágenes en movimiento creadas mediante técnica digital que aparecen en pantalla de forma automática y que intentan dotar de mayor dinamismo a la publicación); el botón (icono específico que atrae al usuario para ser pulsado y que ocurra algo en la publicación), el audio (archivo sonoro que reproduce un sonido en concreto) y el vídeo secuencia de imágenes en movimiento que se reproducen dentro de la publicación. Tras la investigación realizada se puede señalar que la tipología de elemento utilizado es el botón en el $100 \%$ de los contenidos analizados.

En cuanto a los modelos de interacción posibles: scroll (acción que requiere la interacción del usuario para desplazar un texto o una imagen); brush (ac- ción que sirve para, a través del movimiento del dedo, realizar el efecto de borrado para que debajo del contenido inicial aparezca otro diferente por el trazado que haya realizado el usuario con su dedo — si está en móvil o tableta - o ratón — si está visualizando la versión PC-; pinta (acción que sirve para, a través del movimiento del dedo, realizar el efecto de lápiz para colorear o hacer cambiar el contenido según el trazado que haya realizado el usuario con su dedo; pulsa (acción de encender un contenido. Tocando con el dedo o ratón se logrará accionar ese contenido en concreto); desliza (acción de pasar suavemente un contenido para poder ver otro por la pantalla de la publicación); arrastra (llevar un elemento hacia otro para desbloquear un contenido) y, por último, sin interactividad (contenidos como ilustraciones o infografías que pueden aparecer estáticas y no disponer de la capacidad de interacción con el usuario para hacer aparecer en la pantalla nuevos contenidos o detalles). Tras el estudio realizado se puede señalar que el efecto de interactividad empleado en el $100 \%$ de los casos integrantes de la muestra es el denominado 'pulsa'.

\section{G. Desde el punto de vista del número de vi- sitas/usuarios}

La investigación realizada ha permitido obtener el dato de que el número medio de usuarios que han accedido a cada juego en MARCA Plus es 203.126, de los cuales, una media de 126.883 han completado el juego, o lo que es lo mismo, un 62,46\%. Estos datos han sido 
facilitados por la propia revista. Los relativos al número de lectores/usuarios que han accedido al juego y el tiempo de permanencia proceden de las herramientas de analítica web Google Analitycs y Adobe Analitycs (también conocida como Omniture, herramienta de medición adquirida por la empresa editora de la revista). Los datos sobre si los juegos han sido completados o no por los usuarios proceden del plugin de Aquafadas.

\section{H. Desde el punto de la duración del juego}

En lo que a la duración del juego se refiere hay que indicar que la media se sitúa en 1 minuto y 27 segundos, siendo de 28 segundos el tiempo mínimo empleado en completar un juego y de 2 minutos y 25 segundos el máximo. En relación con este dato hay que indicar que el tiempo medio de lectura de un ejemplar completo por parte de un usuario es de 8 minutos y 29 segundos, siendo de 1 hora y 15 minutos el tiempo estimado para leer y disfrutar al completo todos los contenidos de un ejemplar. Estos datos han sido facilitados por MARCA Plus a 15 de marzo de 2018, y representan la media obtenida de los 97 números publicados hasta esa fecha.

\section{Desde el punto de vista de la experiencia de los usuarios}

La opinión de los suscriptores acerca de su experiencia tras la lectura de esta revista se puede resumir del siguiente modo. A la pregunta de si se ha participado en el juego de forma consciente el $70 \%$ de estos ha respondido que sí lo ha hecho. Sobre si consideran que el juego aporta un valor añadido a los contenidos informativos o publicitarios el $90 \%$ se pronuncia a favor. En cuanto a la duración del juego, el 55,6\% opina que es corta, mientras que un $22,2 \%$ opina que es óptima y el mismo porcentaje que es excesiva. En cuanto a si recuerdan algún tipo de juego en particular, el 80\% de los suscriptores contesta que sí. Los más recordados son los que tienen que ver con las adivinanzas (reconocimiento de voces de jugadores, sobre todo, o quien es quien) y test deportivos como por ejemplo, el de unir ciclistas con el año en que ganaron determinadas competiciones deportivas- o las cartas en las que se emparejan opciones - por ejemplo, los políticos con su equipo de fútbol favorito-. También se preguntó a los suscriptores si han recomendado algún tipo de juego, a lo que solo un 30\% respondió que sí, argumentando que "porque les parecen divertidos". Entre el $70 \%$ que no los recomendaron, había suscriptores que señalaban que no lo hicieron porque no se les había ocurrido o porque no era fácil hacerlo en redes sociales.

Dentro de este apartado hay que señalar también que los juegos identificados en la muestra seleccionada apenas generan conversaciones posteriores en redes sociales. De los treinta casos analizados, tan solo uno —el no30 - ha generado dicha conversación, concretamente en Twitter, pero tan sólo con dos tuits. El juego consistía en que el usuario debía adivinar a quien pertenecía el torso desnudo del futbolista que aparecía en una fotografía. 
Hay que señalar también que a la pregunta de si el jugador obtiene recompensa, puntos o premios, la respuesta es no en el total de los casos analizados. No obstante, se ha podido averiguar que esto sí sucede en tres casos, todos ellos fuera de la muestra, y se plantea por motivos comerciales. Por ejemplo, concretamente en el $\mathrm{n}$ ํ77 se pide al lector/usuario que busque unas gafas de sol por la revista, haga una captura de pantalla una vez encontradas, y envíe la imagen a una dirección de correo de la publicación para entrar en un sorteo de ese producto.

\section{Discusión y Conclusiones}

Los resultados de la investigación realizada han puesto de manifiesto que la revista nativa digital MARCA Plus, a pesar de ser un medio de referencia en el panorama de la innovación periodística en España, no emplea narrativas gamificadas a la hora de ofrecer a sus lectores contenidos informativos, si bien, sí hemos podido constatar el empleo de los juegos como una extensión de la información, cuya inclusión o exclusión, no afecta al entendimiento del relato periodístico, pero sí lo complementa ofreciendo al lector una experiencia de carácter lúdico. Hay que señalar que, además, lo hace en todas sus versiones, independientemente del soporte empleado (ordenador, tableta o teléfono móvil).

Sin embargo, hemos podido constatar en nuestra investigación que la incorporación de dichos elementos de juego en los contenidos publicitarios está todavía por explotar. Entre los ejemplares que componen la muestra no ha sido posible observar ningún caso en el que se incorporen elementos propios de los juegos en las inserciones publicitarias, lo que nos da una idea de que los anunciantes no valoran aún el potencial que tendría el introducir dinámicas de gamificación en sus productos o servicios. De este modo, podemos concluir que la Hipótesis 1 se confirma tan solo de manera parcial. En este sentido, señalar también que llama la atención la reducida media de juegos incluidos por cada ejemplar de la cabecera analizada, ya que es inferior a dos por ejemplar.

El empleo de elementos propios de los juegos potencia la motivación y capta el interés de la audiencia, sitúa al lector/usuario en el centro de la experiencia informativa, al tiempo que convierte la lectura de productos informativos en una actividad amena y divertida; atrae a audiencias jóvenes y favorece la creación de un hábito de lectura; potencia el consumo de noticias y fidelizan lectores/usuarios. Con la incorporación de los juegos, la lectura se convierte en una experiencia audiovisual interactiva en la que el lector/ usuario puede ser parte activa del hecho comunicacional. Estos juegos destacan porque ofrecen una interfaz sólida y muy cuidada desde el punto de vista del diseño y sus elementos esenciales (tipografía, imagen y color), al tiempo que ofrece unas interacciones de sencilla interpretación, muy intuitivas, lo que favorece la usabilidad y la experiencia de usuario. Si bien través del empleo de juegos interactivos 
como extensión del relato periodístico, MARCA Plus genera experiencias atractivas que inspiran a la acción e involucran al lector/usuario, todavía éste no se siente motivado a expresar y compartir su experiencia a través de las redes sociales, con lo que la $\mathrm{H} 2$ queda refutada.

\section{Bibliografía}

Burke, B. (2014). Gamify: How Gamification Motivates People to do Extraordinary Things. Massachusetts: Bibliomotion, Inc.

Deterding, S. (2011). Situated Motivational Affordances of Game Elements: A Conceptual Model. Hamburgo: Hans Bredow Instiute for Media.

Deterding, S., Dixon, D., Khaled, R., \& Nacke, L. (2011). From game design elements to gamefulness: defining gamification. In Proceedings of the 15th International Academic MindTrek Conference: Envisioning Future Media Environments (pp. 9-15). ACM. doi: http://dx.doi. org/10.1145/2181037.2181040

Deterding, S., Sicart, M., Nacke, L., O’Hara, K., \& Dixon, D. (2011, May). Gamification. Using Game-Design Elements in Non-Gaming Contexts. In CHI'11 Extended Abstracts on Human Factors in Computing Systems (pp. 2425-2428). ACM.

Ferrer Conill, R. (2016): Points, badges, and news. A study of the introduction of gamification into journalism practice. En Comunicació: Revista de Recerca i d'Anàlisi [Societat Catalana de Comunicació] http://revistes.iec.cat/index.php/TC. Vol. 33 (2) (novembre 2016), pp. 4563. DOI: $10.2436 / 20.3008 .01 .148$

FUNDEU (2012). Ludificación, mejor que gamificación como traducción de gamification. En Fundación del Español Urgente. Recuperado de: https:/www.fundeu.es/recomendacion/ ludificacion-mejor-que-gamificacion-como-traduccion-de-gamification-1390.

García-Ortega, A. y García-Avilés, J. A. (2018a). Los newsgames como estrategia narrativa en el periodismo transmedia: propuesta de un modelo de análisis. Revista Mediterránea de Comunicación/Mediterranean Journal of Communication, 9(1).

García-Ortega, A. y García-Avilés, J. A. (2018b). Gamificación del contenido periodístico para mejorar el engagement: análisis de cuatro casos de éxito. En González Esteban, J. L. y García-Avilés, J. A. (Ed.), Mediamorfosis: Radiografía de la Innovación en el periodismo (pp.151174). Elche: SEP.

Herger, M. (22 de septiembre de 2014). How Gamification Design Thinking Helps Your Business (http://goo.gl/49vCNR) (2015-04-18).

Huizinga, J. (1938). Homo Ludens. Haarlem: Tjeenk Willink y zoon N.V.

Kapp, K. (2012). The Gamification of Learning and Instruction: Game-Based Methods and Strategies for Training and Education. New Jersey: John Wiley y Sons.

Karapanos, E., Zimmerman, J., Forlizzi, Malone, T. (1980). What Makes Things Fun to Learn? Heuristics for Designing Instructional Computer Games. In Proceedings of the 3rd ACM SIGSMALL symposium and the first SIGPC symposium on Small systems, pp. 162-169.

Labarga-Adán, I.; González-Díez, L. y Pérez-Cuadrado, P. (2018). Revistas nativas digitales en el ámbito del deporte en España: el caso de MARCA Plus. Revista Mediterránea de 
Comunicación/ Mediterranean Journal of Communication, 9(1), 451-463. doi: https://www.doi. org/10.14198/MEDCOM2018.9.1.29

Marczewski, A. (2015). Even Ninja Monkeys Like to Play. San Francisco: Blurb, Inc.

Martínez Cano, F. J. (2016a): Newsgames: nuevas tendencias en el periodismo ibérico. Ponencia presentada en el III Congreso de la Sociedad Española para las Ciencias del Videojuego. Barcelona, junio 2016.

Martínez Cano, F. J. (2016b). Series de ficción y videojuegos: transmediatización y gamificación de los discursos audiovisuales contemporáneos. Index.comunicación. Revista científica de comunicación aplicada, 6(2), 287-295.

Paharia, R. (2013). Loyalty 3.0: How to Revolutionize Customer and Employee Engagement with Big Data and Gamification. New York: McGraw-Hill Education.

Ramírez, J.L. (2014). Gamificación, Mecánicas de juegos en tu vida personal y profesional. Madrid: Sclibro.

Rieber, L.P. (1996). Seriously considering play: Designing interactive learning environments based on the blending of microworlds, simulations, and games. Educational Technology Research and Development, June 1996, Volume 44 (2), 43-58. doi:10.1007/ BF02300540

Rodríguez-Fernández, L. (2017). Smartphones y aprendizaje: el uso de Kahoot en el aula universitaria. Revista Mediterránea de Comunicación/Mediterranean Journal of Communication, 8(1), 181-190. doi: 10.14198/MEDCOM2017.8.1.13

Rojas Torrijos, J. L. (2018). La estrategia digital de internacionalización de Marca en Latinoamérica. Estudio de caso de MARCA Claro en México. Revista de Comunicación, 17 (1), pp. 133-154. doi: 10.26441/RC17.1-2018-A7.

Rojas Torrijos, J. L. (2015). Nuevos horizontes del periodismo deportivo español: primeras revistas para móviles y tabletas en los diarios Marca y Sport. Fonseca, Journal of Communication, n10, pp.29-49.

Salaverría Aliaga, R.; Martínez-Costa Pérez, M.P. y Breiner, J. (2018). Map of digital news media at Spain in 2018: quantitative analysis. Revista Latina de Comunicación Social, 73, pp. 1034 a 1053. http://www.revistalatinacs.org/073paper/1295/54en.html doi: 10.4185/RLCS-2018-1295-54en

Siapera, E. (2012). Understanding New Media. London: SAGE.

Torres-Toukoumidis, A. (2016). Evaluación de políticas públicas con técnicas de gamificación para la educación ciudadana. Tesis doctoral. Universidad de Huelva.

Werbach, K. y Hunter, D. (2012). For the Win: How Game Thinking Can Revolutionize Your Business. Wharton Digital Press, Philadelphia (PA).

World Gamification Map (2006). Recuperado de: http://www.gamificationworldmap.com.

Zichermann, G., \& Linder, J. (2013). The Gamification Revolution: How Leaders Leverage Game Mechanics to Crush the Competition. Nueva York, EEUU: McGraw-Hill Professional. 